Check for updates

The BMJ

Cite this as: BMJ 2022;376:0104 http://dx.doi.org/10.1136/bmj.o104 Published: 14 January 2022

\section{Sixty seconds on ... covid-19 and sex}

Mun-Keat Looi

\section{Let's get it on}

Steady on there. Although you might have expected rates of sexual activity to have gone up during lockdown, the opposite is the case, judging by the plight of the world's leading condom makers.

\section{Nothing for the weekend?}

So it seems. Karex Berhad, the company that makes one in five condoms sold globally, has seen sales drop by over $40 \%$ over the past two years. ${ }^{1}$ This despite optimism from its chief executive that the lockdowns of 2020 meant that people having "nothing to do but have sex" and others abstaining from having children during a crisis would fuel "double digit" growth in demand.

\section{Disappointing performance}

Not everyone was optimistic. Durex's chief executive said as early as April 2020 that increased anxiety and a drop in dating and hook-ups was decreasing "the number of intimate occasions," leading to a fall in condom sales. $^{2}$

\section{Where's the evidence?}

A meta-analysis of seven studies from China, Italy, Turkey, the UK, and the US published in the journal Sexologies last year verified "a decrease in sexual activity, which indicates the impairment of the individuals' quality of sexual life."3

\section{Can you go any further?}

A small 2021 study in Indonesia showed a decrease in "overall mood scale and sexual activity frequency" during the pandemic. ${ }^{4}$ The authors suspect that feelings of anxiety, boredom, confusion, depression, fear, irritability, and isolation, as well as job and income losses, were to blame.

\section{That's ruined the mood}

Indeed. Perhaps the biggest impact came from the worldwide pausing of sexual health clinics and cancelled orders for condoms. Karex's chief executive pointed to the NHS shutting down its sexual wellness clinics, which normally hand out free condoms. Kristin Mitchell of the University of Glasgow, who leads the covid-19 study in the National Survey of Sexual Attitudes and Lifestyles, said, "Our findings [from four months into the pandemic] are that only a quarter of participants not in steady relationships reported partnered sex since lockdown.” Preliminary data from later months indicates that "in the first year of the pandemic people had less sex, fewer partners, and fewer new partners."

\section{So big rubber lost money?}

There is an upside. Things got so bad that Karex had to switch to making other products, such as rubber gloves-booming in the new market for personal protective equipment-to make up the shortfall.

\footnotetext{
Prem Kumar P. Malaysia's Karex: Covid lockdowns dented condom demand. Nikkei Asia. 3 January 2022. https://asia.nikkei.com/Editor-s-Picks/Interview/Malaysias-Karex-COVID-lockdowns-dented-condom-demand.

2 Subramanian S. The world's largest condom manufacturer has had a surprisingly bad pandemic. 10 January 2022. https://qz.com/2111029/the-worlds-largestcondom-maker-had-a-surprisingly-bad-pandemic.

3 Delcea C, Chirilă VI, Săuchea AM. Effects of covid-19 on sexual life: a meta-analysis. Sexologies 2021;30:e49-54doi: 10.1016/j.sexol.2020.12.001.

4 Kusuma AHW, Brodjonegoro SR, Soerohardjo I, Hendri AZ, Yuri P. Sexual activities during the covid-19 pandemic in Indonesia. Afr J Urol 2021;27:116. doi: 10.1186/s12301-021-00227-w pmid: 34421293
} 